\title{
Perceived organisational support and well-being: The role of psychological capital as a mediator
}

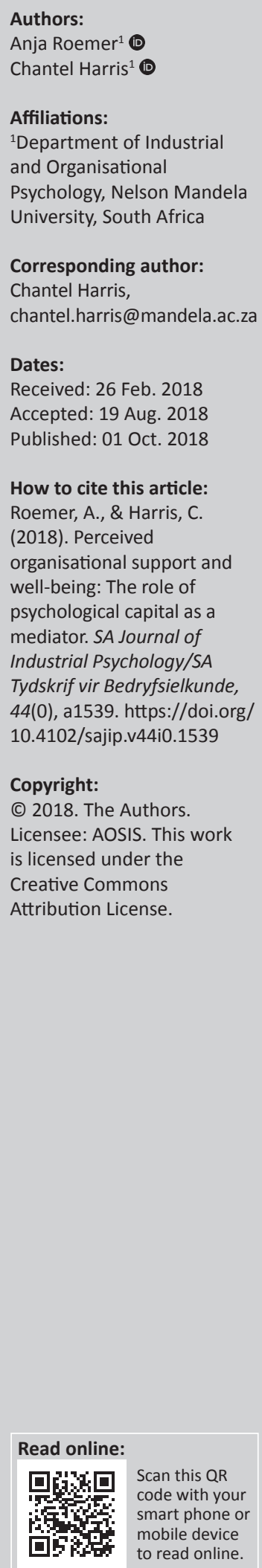

Orientation: Today's competitive work environment requires organisations and employees to successfully cope with challenges to maintain healthy levels of well-being. It is, therefore, imperative to investigate which organisational and psychological factors contribute to well-being in employees.

Research purpose: This study served to analyse whether psychological capital (PsyCap) mediates the relationship between perceived organisational support (POS) and well-being.

Motivation for the study: In light of the positive psychology movement, this study aimed to investigate how positive constructs actively contribute to employee well-being. Knowledge of organisational and psychological factors that enhance well-being in employees will be of great benefit to organisations that aim to create positivity in the workplace in order to avoid the negative consequences of work-related stress and a toxic work environment.

Research approach/design and method: A cross-sectional, non-experimental design, applying convenience and snowball sampling, was used to recruit 159 South African employees who completed an online survey that assessed the constructs under investigation.

Main findings: It was found that POS, PsyCap and well-being are positively correlated to one another. Moreover, hierarchical regression analyses revealed that PsyCap fully mediates the relationship between POS and well-being.

Practical/managerial implications: These findings imply that organisations should be committed to target their employees' PsyCap to enhance well-being in their workforce.

Contribution/value-add: The findings show that it is not sufficient just to provide organisational support to enhance well-being. Organisations also need to acknowledge the important role of their employees' PsyCap to ensure that they are well equipped to deal with challenges in the workplace while maintaining healthy levels of well-being.

\section{Introduction}

The discipline of psychology has focused to a great extent on the treatment of dysfunctional behaviour. As a consequence, the studies of organisational behaviour were also preoccupied with research on the negative aspects of employee behaviour, such as counter-productive behaviour, work stress and burnout (Youssef-Morgan \& Luthans, 2015). The negative consequences of work-related stress not only have a negative impact on the well-being of employees but also on organisations. Poor employee well-being is related to low levels of organisational commitment (Matin, Kalali, \& Anvari, 2012), more absenteeism (Olivares-Faúndez, Gil-Monte, Mena, JélvezWilke, \& Figueiredo-Ferraz 2014), a decrease in productivity (Dewa, Loong, Bonato, Thanh \& Jacobs, 2014), low job satisfaction and increased turnover intentions (Smoktunowicz et al., 2015). It should, therefore, be in the interest of organisations to create a work environment that contributes to employee well-being. Competition in global markets and stress in the workplace cannot be avoided, but how individuals deal with challenging demands can be influenced.

The job demands-resources (JD-R) theory proposes that job resources and personal resources buffer the negative effects of job demands and that job demands increase the motivational effects of resources (Bakker \& Demerouti, 2014). The conservation of resources (COR) theory suggests that resources accumulate and protect individuals from resource loss, which facilitates dealing with stress (Hobfoll, 1989). Based on these theories, the present study aims to investigate how POS, seen as a job resource, and the personal resource of psychological capital (PsyCap), a higher order construct consisting of the facets of self-efficacy, hope, resilience and optimism, interact in order to contribute to well-being in employees. 


\section{Background to the study}

Positive psychology aims to investigate positive qualities and factors that contribute to growth and well-being (Seligman \& Csikszentmihalyi, 2000). This offers a valuable approach to target the issue of stress and its negative consequences in the workplace. Absenteeism, decreased productivity and low levels of organisational commitment as a result of low levels of health cause financial costs that can be avoided. The absence of ill-being, however, cannot be equated with the presence of well-being (Achor, 2011). It is, therefore, important to analyse which organisational and personal variables assist employees in dealing with challenges and stress to actively enhance well-being and maintain health. The positive constructs of POS and PsyCap are factors that might contribute to higher levels of well-being. POS refers to the perceptions of employees regarding the extent to which their organisation expresses appreciation and concern in terms of their wellbeing (Eisenberger, Huntington, Hutchison, \& Sowa, 1986). PsyCap is referred to as a person's psychological state of development. It is a higher order construct consisting of the facets of self-efficacy, hope, resilience and optimism (Luthans, Youssef-Morgan, \& Avolio, 2015). Previous research showed that POS, as well as PsyCap, are positively related to well-being (Avey, Luthans, Smith, \& Palmer, 2010; Caesens, Stinglhamber, \& Ohana, 2016; Malinowski \& Lim, 2015). It is assumed that job resources assist personal resources to develop and flourish (Xanthopoulou, Bakker, Demerouti, \& Schaufeli, 2007). If POS is seen as a job resource and PsyCap as a personal resource, it can be argued that POS works in favour of PsyCap. There is evidence that POS and PsyCap are positively linked to each other (Azim \& Dora, 2016; Sihag \& Sarikwal, 2015). Based on these research findings, it is assumed that PsyCap acts as a mediator in the relationship between POS and well-being. Other studies could already show that PsyCap mediates the relationship between instructor support (Nielsen, Newman, Smyth, Hirst, \& Heilemann, 2017) and well-being, as well as the relationship between social support (Li et al., 2014) and well-being. PsyCap also has a mediating effect between POS and depressive symptoms (Liu, Hu, Wang, Sui, \& Ma, 2013). These studies indicate that PsyCap plays a significant role between support and well-being, but to date no study has investigated the mediating role of PsyCap between POS and positive well-being. The present study aims to target this gap in the existing body of research.

\section{Research objectives}

The primary objective of the study is to investigate the relationship between POS, PsyCap and well-being. Organisations are often committed to offer support that contributes to the well-being of their employees. It will be valuable to analyse the underlying mechanism that accounts for the positive effect of POS on well-being. It is proposed that organisational support might fuel a positive mindset, which is characterised by high levels of self-efficacy, hope, resilience and optimism. These four personal resources make up the higher order construct of PsyCap. Employees high in PsyCap might have the attitude, energy and strength that protect them from the negative consequences of stress in the workplace and might, therefore, experience higher levels of well-being. This study therefore aims to address the question as to whether PsyCap plays a mediating role in the relationship between POS and well-being. The following section will outline the constructs under investigation and the theoretical framework that supports the assumed relationship of these constructs.

\section{Literature review Perceived organisational support}

Perceived organisational support refers to employees' perceptions regarding the extent to which their organisation appreciates their effort and cares about their well-being (Eisenberger et al., 1986). POS incorporates the employee's belief that appreciation is expressed through payment, job enrichment, recognition and other forms of benefits. Concern regarding employee well-being is also shown through the offer of organisational policies and human resources practices that facilitate meeting and balancing job demands, and demands outside work (Worley, Fuqua, \& Hellman, 2009).

Perceived organisational support meets the employee's socio-emotional needs, which contribute to the identification with the organisation, affective commitment (Kurtessis et al., 2017) and positive affect (Caesens et al., 2016). The principle of reciprocity from the social exchange theory also explains the positive consequences of POS. If employees feel supported, they are likely to return the appreciation by showing good performance, which in turn raises the expectation to be rewarded for it (Kurtessis et al., 2017). The principle of reciprocity is also applied if a lack of support or even abusive treatment by the organisation is evident. Unfavourable treatment is likely to result in poor employee behaviour (Cohen-Charash \& Mueller, 2007).

Factors that influence perceptions of organisational support are supervisor behaviour, the quality of relationship between the employee and the organisation, and human resource practices (Kurtessis et al., 2017). A supervisor acts as the representative of the organisation, and for this reason, supportive supervisor behaviour is a good predictor of POS (Kurtessis et al., 2017). The quality of the relationship is also an important factor influencing POS. It is proposed that the psychological contract between the organisation and the employee moderates the relationship between favourable or unfavourable treatment and POS (Aselage \& Eisenberger, 2003). The psychological contract between an employee and the organisation refers to perceptions in terms of what they owe each other (Robinson, 1996). When an employer treats an employee favourably, exceeding the expectations of the psychological contract, POS will be higher (Aselage \& Eisenberger, 2003). For this reason, it is important that employees attribute the organisation's support to their sincere concern regarding the well-being of employees. Kurtessis et al. (2017) in a meta-analysis identified that certain organisational policies and human resource practices are 
positively related to POS. Identified factors were opportunities for development, job security, family supportive policies, job enriching characteristics, autonomy and participation in decision-making (Kurtessis et al., 2017).

Establishing a supportive organisational environment is a valuable investment for employers. Research has shown that POS is positively linked to employee engagement and wellbeing (Caesens et al., 2016) and negatively related to burnout (Walters \& Raybould, 2007). It is, therefore, valuable for organisations to implement support structures to achieve desirable outcomes such as well-being in employees.

\section{Psychological capital}

Psychological capital incorporates the four distinct dimensions of self-efficacy, hope, resilience and optimism. Psychological capital is a higher order construct, which implies that PsyCap's distinct dimensions also share some variance or commonality, which make up the higher order factor. This commonality across PsyCap's dimensions contributes to motivation, desirable attitudes, task and goal accomplishment (Luthans, Avolio, Avey, \& Norman, 2007). It is proposed that PsyCap's higher order structure represents one's 'positive appraisal of circumstances and probability for success based on motivated effort and perseverance' (Luthans et al., 2007, p. 550). In addition, PsyCap is considered to be a state-like construct, which means that it is malleable and can be developed within the individual (Luthans et al., 2007). There are face-to-face and web-based interventions that were shown to enhance an individual's level of PsyCap (Luthans, Avey, Avolio, \& Peterson, 2010; Luthans, Avey, \& Patera, 2008). This malleability is an important characteristic, because organisations might be able to influence and develop the PsyCap of their employees. The four dimensions of PsyCap will be outlined in the following sections.

\section{Self-efficacy}

Self-efficacy is defined as one's perception regarding his or her ability to execute required tasks successfully (Bandura, 1982) and involves the mobilisation of those cognitive resources that facilitate the required or desired performance (Stajkovic \& Luthans, 1998). Luthans et al. (2015) emphasise that individuals high in self-efficacy feel energised and are motivated to accomplish challenging tasks. Resources, and organisational resources, are strong predictors of selfefficacy in employees, given the case that employees do not suffer from role overload (Brown, Jones, \& Leigh, 2005). Highly efficacious individuals make use of self-regulatory processes that assist in the reduction of negative emotions because of stress. High levels of self-efficacy, therefore, protect employees from negative consequences that might arise from a stressful work environment (Fida, Paciello, Tramontano, Barbaranelli, \& Farnese, 2015).

\section{Hope}

Hope refers to a cognitive state that drives the goal pursuit process by allowing individuals to set challenging goals and finding ways to achieve these goals (Luthans et al., 2015). Hope consists of an agency component and a pathways component. Agency refers to the mental willpower to achieve a goal. Pathways refer to actions that successfully lead to goal accomplishment. The pathways component also involves the ability to seek alternative ways to goal accomplishment in case the circumstances require it (Snyder, 2002). Individuals who obtain high levels of hope will think of other ways that help them to achieve a goal when the initial route to goal attainment gets blocked. A certain degree of self-control and self-regulatory behaviour is crucial for effective agency and pathways thinking (Vohs \& Schmeichel, 2002), in order to manage cognitions, feelings and behaviour that would interfere with goal attainment (Inzlicht, Schmeichel, \& Macrae, 2014). High levels of hope, which are characterised by the aforementioned positive cognitive processes, are negatively linked to depression and positively linked to wellbeing (Alarcon, Bowling, \& Khazon, 2013). Hope might, therefore, be a valuable personal resource that contributes to employee well-being.

\section{Resilience}

There are many definitions of resilience, but most of them share the view that one must show adaption and/or growth in the face of adversity (Britt, Shen, Sinclair, Grossman, \& Klieger, 2016). Individuals who have faced stress or trauma often experience mental and physical issues or even develop a post-traumatic stress disorder. Research shows that individuals might also experience positive mental outcomes after having faced severe adversity, referring to it as post-traumatic growth. Post-traumatic growth describes a process of individual development, which goes beyond recovery to the individual's pre-traumatic state (Zoellner \& Maercker, 2006). When applied to work, resilience can be defined as 'a developmental trajectory characterized by demonstrated competence in the face of, and professional growth after, experiences of adversity in the workplace' (Caza \& Milton, 2012, p. 896). Luthans et al. (2015) emphasise that risk factors and adversity should not be regarded as a threat, but rather be seen as a chance to develop skills that would have been undiscovered without the presence of difficulties, which might possibly result in personal growth. The acquisition of these skills helps to successfully cope with future challenges. Individuals who obtain high levels of resilience are, therefore, more likely to experience higher levels of well-being (Souri \& Hasanirad, 2011).

\section{Optimism}

Optimism can be regarded as general positive expectations regarding the future (Carver, Scheier, \& Segerstrom, 2010), as well as a specific explanatory style that attributes failure and setbacks to external, temporary circumstances. Success, in contrast, is attributed to internal and stable factors (Seligman, 2002). Both views are considered important because positive expectations only manifest in PsyCap optimism if correct attributions are made as to why specific events occur (Luthans et al., 2015). Luthans et al. (2015) highlight an important characteristic of PsyCap optimism as the ability to adjust 
one's level of optimism when the circumstances require it. Consistently attributing failure to external factors is dangerous and might bias perceptions of reality. Moreover, individuals should also be able to show gratitude regarding external variables that have contributed to success (Luthans et al., 2015). Optimistic individuals focus on the positive aspects of life by showing leniency for happenings in the past, being appreciative of the present and by seeking beneficial opportunities in the future (Schneider, 2001). Because of these positive cognitions, optimists are more likely to experience higher levels of well-being and lower levels of distress (Desrumaux et al., 2015).

\section{Well-being}

The term 'well-being' is commonly used in daily life and everyone might have a slightly different understanding of what well-being incorporates. For this reason, it is important to outline how well-being was defined and conceptualised in the present study. Scientific discussions regarding well-being often refer to hedonic and eudaimonic well-being. These two well-being concepts evolved from distinct philosophical perspectives. Aristippus, an ancient Greek philosopher, as well as the English philosophers Thomas Hobbes and Jeremy Bentham, understood well-being as hedonism, which focuses on the experience and maximisation of pleasure (Ryan \& Deci, 2001). Hedonic well-being is, therefore, regarded to be affective in nature. The Greek philosopher Aristotle, in contrast, stated that life should be about more than the simple experience of pleasure and positive affect. He proposed that an individual should rather strive to become the best he or she can be in order to achieve high levels of well-being, which is referred to as eudaimonia (Ryff \& Singer, 2008). Eudaimonic well-being is rather regarded as being cognitive in nature, where individuals show positive psychological functioning and are motivated to strive towards their full potential (Waterman, Schwartz, \& Conti, 2008).

Although it is popular to assess hedonic and eudaimonic well-being separately, it remains questionable whether hedonia and eudaimonia, which are based on different philosophies, are distinct constructs from a scientific point of view. Two recent studies have investigated whether hedonic and eudaimonic well-being differ from a psychometric and scientific perspective (Disabato, Goodman, Kashdan, Short, \& Jarden, 2016; Longo, Coyne, Joseph, \& Gustavsson, 2016). Both studies found that hedonic well-being and eudaimonic well-being possess low discriminant validity because of high correlations between these constructs. These findings indicate that the distinction between hedonia and eudaimonia is rather a philosophical than a scientific one. It is suggested that well-being is rather seen as one general well-being factor that incorporates hedonic as well as eudaimonic aspects (Longo et al., 2016). Consequently, well-being in the present study was assessed with a unidimensional measure that includes hedonia as well as eudaimonia.

Research has shown that employee well-being is linked to desirable outcomes, such as higher levels of productivity
(Oswald, Proto, \& Sgroi, 2015) and less absenteeism because of sick-leave (Straume \& Vittersø, 2015). Consequently, organisations should be interested in promoting and maintaining their employees' well-being. Employees who experience positivity and express high levels of positive psychological functioning are valuable assets to any organisation. It is, therefore, imperative to analyse organisational and personal factors that contribute to employee well-being.

\section{Relationships between constructs}

This study aims to analyse how POS, PsyCap and well-being relate to one another. The following section will outline the theoretical frameworks that underpin the proposed relationship between the three variables of interest.

The JD-R theory takes job demands, job resources and personal resources into account to make predictions regarding well-being and performance (Bakker \& Demerouti, 2014). JD-R theory assumes that job demands and job resources facilitate different processes. Job demands are predictors of health impairment, such as physical exhaustion and psychosomatic symptoms, while job resources predict motivational processes. In addition to that, job demands and job resources interact in two ways: Bakker and Demerouti (2014) state that resources, on the one hand, buffer the negative effects of job demands, and that demands on the other hand, can enhance the motivational effects of resources by making them more salient in challenging situations. This means that employees who feel supported while dealing with challenging demands are less likely to show symptoms of health impairment and might exhibit greater positive psychological functioning. Moreover, JD-R theory acknowledges the importance of personal resources. Bakker and Demerouti (2014) outline that interventions and training, which can also be considered a form of organisational support, are useful ways to enhance the personal resources of employees, particularly referring to Luthans et al.'s (2010) PsyCap intervention. Previous research has shown that the personal resources of self-efficacy and optimism are partial mediators in the relationship between job resources and engagement (Xanthopoulou et al., 2007). This finding implies that job resources might help personal resources to flourish.

Hobfoll's (1989) COR theory states that individuals are interested in accumulating, maintaining and protecting resources, which assist them in dealing with stress. The COR theory acknowledges that resources seldom occur separately; they rather tend to accumulate and reinforce each other in caravan passageways (Chen, Westman, \& Hobfoll, 2015). Chen et al. (2015) define caravan passageways as those environmental circumstances that help to foster and protect resources. As a consequence, a supportive organisational environment will help employees to accumulate and sustain resources, for instance by enhancing personal resources. With reference to the JD-R and the COR theory, the potential positive relationship of POS, PsyCap and well-being can be explained. 
Perceived organisational support can be regarded as a job resource and PsyCap as a personal resource. Job resources are related to overall well-being by buffering the negative effects of job demands. Moreover, job resources initiate motivational processes (Bakker \& Demerouti, 2014). Motivational processes relate to an individual's interest in personal growth and level of psychological functioning, which form part of well-being in the present study. In addition to that, support creates a feeling of security in case help is needed and fulfils the employee's socio-emotional needs, which is associated with positive affect, which is also regarded as a facet of well-being (Caesens et al., 2016). This means, with regard to POS, the employees who perceive to have higher levels of organisational support are more likely to experience higher levels of well-being. This assumption lays the foundation for the first hypothesis:

\section{$\mathbf{H}_{\mathbf{1}}$ : POS is positively related to well-being.}

Job resources fuel personal resources (Xanthopoulou et al., 2007). With reference to the concept of caravan passageways, it is suggested that organisational support contributes to an organisational environment that enriches, fosters and protects resources, such as personal resources (Chen et al., 2015). With regard to the present study, it is proposed that a supportive organisation creates conditions that enhance its employees' PsyCap:

$$
\mathbf{H}_{2} \text { : POS is positively related to PsyCap. }
$$

Personal resources such as PsyCap facilitate the accurate appraisal of the current situation. The positive cognitive and behavioural processes of PsyCap's facets are, therefore, a significant predictor of well-being (Avey et al., 2010). Employees high in PsyCap are able to interpret situations in a positive and beneficial manner, feel motivated and energised, and have the ability to show adaption in the face of adversity, which leads to the third hypothesis:

$$
\mathbf{H}_{3} \text { : PsyCap is positively related to well-being. }
$$

It is proposed that a supportive organisation will create a positive environment that enables PsyCap to flourish. The personal resource of PsyCap helps employees deal with challenges and to cope with stress because of its beneficial cognitive and behavioural processes, which in turn result in higher levels of well-being. It is, therefore, proposed that the relationship between POS and well-being is mediated by PsyCap.

$\mathbf{H}_{4}$ : PsyCap mediates the relationship between POS and wellbeing:

\section{Method}

The present study applied a non-experimental, cross-sectional design using an online survey for the purpose of data collection.

\section{Research participants}

Convenience and snowball sampling methods were utilised to recruit a non-probability sample of South African employees.
This sampling method was used to gain a sample from a variety of professions. Recruiting participants from a single organisation was avoided to reduce bias in the measures, as POS, in particular, may be subject to social desirability (Boateng, 2014). Individuals were eligible to participate in the survey if they were South Africans who were employed, but not self-employed. Table 1 displays the participants' demographic data. The final sample consisted of 159 participants. More than one-third (35.2\%) were younger than 30 years old; $22.6 \%$ were between 30 and 39 years old, $16.4 \%$ were between 40 and 49 years old, $14.5 \%$ were aged between 50 and 59 , while $11.3 \%$ were 60 years or older. The majority of respondents were either Afrikaans- (46.5\%) or English- (39.6\%) speaking, and $47.2 \%$ of the respondents were married. With regard to educational qualifications, $54.7 \%$ indicated that they had obtained a matric, a diploma or a certificate degree as their highest qualification, while $43.5 \%$ had a university degree. The respondents were working in the field of education $(24.5 \%)$, administration $(20.1 \%)$, health $(11.9 \%)$, engineering/construction $(8.2 \%)$, sales/marketing (10.7\%), finance and/or accounting (6.9\%), human resources $(3.8 \%)$ or another field of occupation $(13.8 \%)$.

TABLE 1: Descriptive statistics of the sample's $(n=159)$ demographic variables,

\begin{tabular}{|c|c|c|c|c|}
\hline Variable & Categories & Frequency & $\%$ & Cumulated $\%$ \\
\hline \multirow[t]{5}{*}{ Age } & $<30$ & 56 & 35.2 & 35.2 \\
\hline & $30-39$ & 36 & 22.6 & 57.9 \\
\hline & $40-49$ & 26 & 16.4 & 74.2 \\
\hline & $50-59$ & 23 & 14.5 & 88.7 \\
\hline & $60+$ & 18 & 11.3 & 100.0 \\
\hline \multirow[t]{2}{*}{ Gender } & Male & 63 & 39.6 & 39.6 \\
\hline & Female & 96 & 60.4 & 100.0 \\
\hline \multirow[t]{4}{*}{ First language } & English & 63 & 39.6 & 39.6 \\
\hline & Afrikaans & 74 & 46.5 & 86.2 \\
\hline & isiXhosa & 21 & 13.2 & 99.4 \\
\hline & isiZulu & 1 & 0.6 & 100.0 \\
\hline \multirow{6}{*}{$\begin{array}{l}\text { Relationship } \\
\text { status }\end{array}$} & Single & 34 & 21.4 & 21.4 \\
\hline & Married & 75 & 47.2 & 68.6 \\
\hline & Relationship & 33 & 20.8 & 89.3 \\
\hline & Divorced & 13 & 8.20 & 97.5 \\
\hline & Widowed & 1 & 0.60 & 98.1 \\
\hline & Other & 3 & 1.90 & 100.0 \\
\hline \multirow{8}{*}{$\begin{array}{l}\text { Highest } \\
\text { qualification }\end{array}$} & Matric & 28 & 17.6 & 17.6 \\
\hline & Diploma & 43 & 27.0 & 44.7 \\
\hline & Certificate & 16 & 10.1 & 54.7 \\
\hline & Bachelor's degree & 23 & 14.5 & 69.2 \\
\hline & Honour's degree & 26 & 16.4 & 85.5 \\
\hline & Master's degree & 11 & 6.90 & 92.5 \\
\hline & Doctorate & 9 & 5.70 & 98.1 \\
\hline & Other & 3 & 1.90 & 100.0 \\
\hline \multirow[t]{8}{*}{ Occupation } & Education & 39 & 24.5 & 24.5 \\
\hline & Health & 19 & 11.9 & 36.5 \\
\hline & $\begin{array}{l}\text { Engineering and/or } \\
\text { Construction }\end{array}$ & 13 & 8.20 & 44.7 \\
\hline & Sales and/or Marketing & 17 & 10.7 & 55.3 \\
\hline & Administration & 32 & 20.1 & 75.5 \\
\hline & Finance and/or Accounting & 11 & 6.90 & 82.4 \\
\hline & Human Resources & 6 & 3.80 & 86.2 \\
\hline & Other & 22 & 13.8 & 100.0 \\
\hline
\end{tabular}
including frequency, percentage and cumulated percentage. 


\section{Measuring instruments}

Data was assessed with a composite questionnaire containing three measures and demographic variables.

The unidimensional and shortened Survey of Perceived Organizational Support (SPOS) (Eisenberger et al., 1986) was used in the present study to assess POS. It consists of eight items, which can be rated on a seven-point Likert scale ( 1 = strongly disagree, 2 = moderately disagree, 3 = slightly disagree, $4=$ neither disagree nor agree, $5=$ slightly agree, $6=$ moderately agree and $7=$ strongly agree). Sample items are the following: 'The organization really cares about my well-being' or 'The organization would ignore any complaint from me $(R)^{\prime}$. The shortened version of the SPOS has shown to be reliable in previous research, with a Cronbach's alpha of 0.91 (Shen et al., 2014).

The Psychological Capital Questionnaire (PCQ-24, Luthans et al., 2007) was used to measure PsyCap in the present study. The questionnaire consists of four subscales measuring self-efficacy, hope, resilience and optimism. Each subscale consists of 6 items, making up 24 items in total, and are rated on a six-point Likert scale $(1=$ strongly disagree, 2 = disagree, 3 = somewhat disagree, $4=$ somewhat agree, $5=$ agree and $6=$ strongly agree). The measure comprises statements, such as: 'I feel confident analyzing a long-term problem to find a solution' (self-efficacy), 'If I should find myself in a jam at work, I could think of many ways to get out of it' (hope) or 'When I have a setback at work, I have trouble recovering from it, moving on' (resilience). ${ }^{1}$

The PCQ-24 has been shown to be a reliable measure for South African samples, exhibiting Cronbach's alphas of 0.83 (self-efficacy), 0.81 (hope), 0.69 (resilience), 0.67 (optimism) and 0.85 (total PsyCap) (Görgens-Ekermans \& Herbert, 2013).

Well-being was assessed with the Warwick-Edinburgh Mental Well-being Scale (WEMWBS, Tennant et al., 2007). It is a unidimensional measure consisting of 14 items that refer to hedonic as well as eudaimonic well-being. The items are rated on a five-point Likert scale $(1=$ none of the time, 2 = rarely, $3=$ some of the time, $4=$ often and $5=$ all of the time) and include statements such as 'I've had energy to spare' or 'I've been feeling cheerful'. Previous research reported Cronbach's alphas of 0.89 and 0.92 and is, therefore, considered a reliable measure (Malinowski \& Lim, 2015; Tennant et al., 2007).

\section{Research procedure and ethical considerations}

An invitation message containing the survey link was sent to contacts. These contacts were asked to forward it to their contacts and the link was also shared on social media platforms. When clicking on the link, participants were

1.Reproduction by special permission of the publisher, Mind Garden, Inc.......... www mindgarden com from the Psychological Capital Questionnaire by Fred Wh. mindgard J. com from the Psychological Capital Question aire by Fred Luthans, Bruce J. Avolio, \& James B. Avey. Copyright $@ 2007$ by Fred Luthans, Bruce J. Avolio, \& James B. Avey. Further reproduction is prohibited without the publisher's written consent. informed about the anonymous and voluntary nature of the study and that obtained data would be treated with confidentiality. Participants were also informed prior to commencement that they had the right to withdraw from the survey at any point in time. No identifiable data were captured by the online survey ensuring the participant's anonymity.

\section{Statistical analysis}

The Statistical Package for Social Sciences version 20 was used to perform the statistical analyses. Means, standard deviations and Cronbach's alphas were calculated to analyse the measures of the assessed constructs and Pearson product-moment correlations were calculated to determine relationships. Hierarchical regression following Baron and Kenny's (1986) causal step approach was applied to analyse a mediating effect. To have a mediating effect, the independent variable, also called predictor (POS), has to be related to the dependent variable (well-being). Furthermore, the independent variable has to be related to the mediating variable (PsyCap), and the mediating variable must also be related to the dependent variable. Full mediation is given if the impact of the independent variable is not significant when controlling for the mediating variable. Partial mediation is given if the impact of the independent variable is significant, but weaker when controlling for the mediator, than it was without the mediator (Baron \& Kenny, 1986). A concern regarding cross-sectional, self-reported data is bias because of common method variance (CMV), which implies that correlations are inflated, owing to the assessment of different constructs at the same time (Lindell \& Whitney, 2001). Harman's one-factor test was conducted in order to test for bias. All items were entered into an exploratory factor analysis. The unrotated factor solution was then analysed regarding a single factor that explains the majority of the variance in the data. If one single factor emerged, this finding might be attributed to the method (Podsakoff \& Organ, 1986).

\section{Results \\ Cronbach's alpha coefficients}

A generally accepted rule to consider a measure reliable is a Cronbach's alpha of 0.70 and higher (Taber, 2017). All measures revealed very high reliability with the SPOS having a Cronbach's alpha of 0.89 , the PCQ-24 showing a Cronbach's alpha of 0.90 and the WEMWBS expressing a Cronbach's alpha of 0.93 . The subscales of the PCQ-24 showed a similar pattern as the one found by GörgensEkermans and Herbert (2013). The subscales of self-efficacy ( $\alpha=0.79)$ and hope $(\alpha=0.84)$ were shown reliable. The subscales of resilience $(\alpha=0.64)$ and optimism $(\alpha=0.67)$ revealed lower internal consistency scores. Cronbach's alpha of the resilience and optimism subscale could be substantially increased (resilience: $\Delta \alpha=0.06$; optimism: $\Delta \alpha=0.05$ ) by removing items 13 and 20 . The reliability of the entire subscales increased to $\alpha=0.70$ for resilience and to $\alpha=0.72$ for optimism. These scores are considered reliable and 
for this reason items 13 and 20 were removed from further analyses, which increased Cronbach's alpha for the entire PCQ-24 to 0.91 .

\section{Descriptive statistics and Pearson product- moment correlations}

Table 2 presents the means, standard deviations and Pearson product-moment correlations for the measures.

The respondents feel supported rather than unsupported by the organisation for which they work, with the SPOS mean score $(M=4.73, S D=1.36)$ exceeding the midpoint of the SPOS scale. The respondents' level of PsyCap and well-being is fairly high, with the PCQ-24 $(M=4.75, S D=0.66)$ and the WEMWBS $(M=3.82, S D=0.70)$ mean scores falling into the upper thirds of their respective scales.

Perceived organisational support is positively correlated to PsyCap $r=0.53, p<0.01$ and to well-being $r=0.42, p<0.01$. PsyCap also shows a positive strong correlation to well-being $r=0.65, p<0.01$. Moreover, PsyCap's facets are significantly and positively related to POS and well-being. POS is positively correlated to self-efficacy $r=0.39, p<0.01$, hope $r=0.50, p<0.01$, resilience $r=0.29, p<0.01$ and optimism $r=0.59, p<0.01$. Well-being is positively correlated to selfefficacy $r=0.36, p<0.01$, hope $r=0.59, p<0.01$, resilience $r=0.56, p<0.01$ and optimism $r=0.69, p<0.01$.

\section{Mediation analysis}

A hierarchical regression was conducted to verify Baron and Kenny's (1986) condition that the independent variable is related to the mediating variable. POS was used as the predictor and PsyCap as the dependent variable. The hierarchical regression is presented in Table 3.

In the first step, all demographic factors were entered into the regression equation as control variables. In the second step, POS as a predictor of PsyCap was added to the regression equation. The first step shows that the demographic variables explain $6 \%$ of the variance in PsyCap. When controlling for the demographic variables in the second step, POS turns out to be a significant predictor of PsyCap $(\beta=0.56, p<0.001)$. POS is able to explain an additional $30 \%$ of the variance in PsyCap. These results show that POS is related to PsyCap and Baron and Kenny's (1986) condition regarding the independent and the mediating variable being related is, thus, met.
To test whether the independent and the mediating variables are related to the dependent variable, another hierarchical regression was conducted. The demographics were used as controls, and POS and PsyCap were entered as predictors of well-being step-wise. The results are presented in Table 4.

In the first step, all demographic factors were entered into the regression equation as control variables. In the second step, POS as a predictor of well-being was added to the regression equation. In the third step, PsyCap was also entered into the regression equation. The first step shows that the

TABLE 3: Hierarchical regression analysis for psychological capital in the sample $(n=159)$, with perceived organisational support as the predictor variable.

\begin{tabular}{lcc}
\hline Variables & Step 1 & Step 2 \\
\hline Controls & & \\
Age & 0.17 & $0.23^{*}$ \\
Gender & -0.04 & -0.08 \\
First language & 0.10 & 0.04 \\
Relationship status & -0.05 & 0.01 \\
Highest qualification & -0.08 & -0.04 \\
Occupation & 0.02 & -0.04 \\
Predictor & & \\
POS & - & $0.56^{* *}$ \\
$R^{2}$ change & 0.06 & $0.30^{* *}$ \\
Total $R^{2}$ & 0.06 & 0.36 \\
Total adjusted $R^{2}$ & 0.02 & 0.33 \\
$F$ Statistic & 1.511 & $11.938^{* *}$ \\
\hline
\end{tabular}

POS, perceived organisational support; $R^{2}$, coefficient of determination.

$*, p<0.05 ; * *, p<0.001$. Standardised regression coefficients.

TABLE 4: Hierarchical regression analysis for well-being in the sample $(n=159)$, with perceived organisational support as the predictor and psychological capital as the mediator.

\begin{tabular}{llll}
\hline Variables & Step 1 & Step 2 & Step 3 \\
\hline Controls & & & \\
Age & 0.07 & 0.12 & -0.01 \\
Gender & -0.12 & $-0.15^{*}$ & -0.11 \\
First language & $0.16^{*}$ & 0.12 & 0.01 \\
Relationship status & -0.08 & -0.06 & -0.05 \\
Highest qualification & $-0.18^{*}$ & $-0.15^{*}$ & $-0.13^{*}$ \\
Occupation & -0.04 & -0.08 & -0.6 \\
Predictor & & & \\
POS & & $0.43^{* *}$ & 0.11 \\
Mediator & & & \\
PsyCap & & & $0.56^{* *}$ \\
$R^{2}$ change & $0.11^{* *}$ & $0.17^{* *}$ & $0.19^{* *}$ \\
Total $R^{2}$ & 0.11 & 0.28 & 0.47 \\
Total adjusted $R^{2}$ & 0.07 & 0.24 & 0.45 \\
$F$ statistic & $2.962^{* *}$ & $8.175^{* *}$ & $16.835^{* *}$ \\
\hline
\end{tabular}

POS, perceived organisational support; $R^{2}$, coefficient of determination; PsyCap, psychological capital. $*, p<0.05 ; * *, p<0.001$. Standardised regression coefficients.

TABLE 2: Correlations for constructs for the sample $(n=159)$.

\begin{tabular}{|c|c|c|c|c|c|c|c|c|c|}
\hline Variables & $M$ & $S D$ & 1 & 2 & 3 & 4 & 5 & 6 & 7 \\
\hline 1. POS & 4.73 & 1.36 & $(0.89)$ & - & - & - & - & - & - \\
\hline 2. PsyCap & 4.75 & 0.66 & $0.53 *$ & $(0.91)$ & - & - & - & - & - \\
\hline 3. Self-efficacy & 4.88 & 0.78 & $0.39 *$ & - & (0.79) & - & - & - & - \\
\hline 4. Hope & 4.74 & 0.82 & $0.50^{*}$ & - & $0.67^{*}$ & $(0.84)$ & - & - & - \\
\hline 5. Resilience & 4.89 & 0.69 & $0.29 *$ & - & $0.62 *$ & $0.64^{*}$ & $(0.70)$ & - & - \\
\hline 6. Optimism & 4.78 & 0.84 & $0.59 *$ & - & $0.52 *$ & $0.69 *$ & $0.50 *$ & $(0.72)$ & - \\
\hline
\end{tabular}

Note: Reliabilities (Cronbach's $\alpha$ ) on the diagonal in parentheses. PsyCap was not correlated with its subscales.

$*, p<0.01$.

$M$, mean; $S D$, standard deviations; POS, perceived organisational support; PsyCap, psychological capital. 
demographic variables account for $11 \%$ of the variance in well-being. When POS is added to the regression equation in step two, it becomes evident that POS is a significant predictor of well-being $(\beta=0.43, p<0.001)$. This fulfils the condition of the independent variable being related to the dependent variable (Baron \& Kenny, 1986). POS accounts for an additional variance of $17 \%$ towards well-being. When PsyCap is entered in the third step, it is revealed that PsyCap is positively related to well-being $(\beta=0.56, p<0.001)$. PsyCap explains an additional $19 \%$ of variance in well-being. This meets Baron and Kenny's (1986) condition of the mediator being related to the dependent variable. The proposed model explains $47 \%$ of variance in well-being in total. Moreover, POS experiences a large decrease in beta weight when adding PsyCap, dropping from $\beta=0.43, p<0.001$ to $\beta=0.11, p=0.13$, which implies that it is no longer a significant predictor of well-being. The insignificance of POS as a predictor of wellbeing when adding PsyCap is an indicator of full mediation.

The results support all the set hypotheses. The data analysis showed that POS is positively correlated to well-being. Moreover, POS is a significant positive predictor of wellbeing (Table 4). H1 is, therefore, supported. POS also turned out to be positively correlated to PsyCap and is also a significant positive predictor of PsyCap (Table 3). For this reason, H2 is supported. Psychological capital exhibits a strong correlation with well-being and is also of predictive value in terms of well-being (Table 4). H3 is, thus, supported. Furthermore, hierarchical regression analysis revealed that PsyCap fully mediates the relationship between POS and well-being. POS is not of predictive value when PsyCap is added to the regression equation when predicting well-being (Table 4). H4 is, therefore, supported.

Harmon's one-factor test was conducted to test for CMV. All items were entered into an exploratory factor analysis. The unrotated solution of the factor analysis extracted 10 factors, with a single factor explaining $32.4 \%$ of the observed variance. The majority of variance is not explained by a single factor, which implies that bias because of CMV is not regarded as a problem in the present study.

\section{Discussion}

Increasing competition in the global markets puts a lot of pressure on organisations and their employees, which might negatively affect employees' well-being. Healthy levels of well-being are a crucial part of working and performing on an optimal level. The fast-paced pressure of the economy cannot be changed, but what can be influenced are organisational and personal factors that help employees to cope with challenges. For this reason, it is important to understand which organisational and personal resources contribute to well-being in employees. The aim of the study was to analyse whether the personal resource of PsyCap acts as a mediator in the relationship between POS and well-being. Based on the JD-R theory and COR theory, it was proposed that a supportive organisational environment would positively impact an employee's PsyCap, which would be related to higher levels of well-being. The present study investigated the relationship of the respective three constructs in a snowball sample of South African employees from a wide range of different occupations.

All measures expressed excellent reliability with Cronbach's alphas ranging from $\alpha=0.89$ to $\alpha=0.93$. The resilience and optimism subscales of the PCQ-24, however, were shown to be less reliable. Reliability of the respective subscales could be substantially enhanced by removing the reverse-coded items 13 and 20. Cronbach's alpha was, thus, improved to a great extent for the resilience $(\Delta \alpha=0.06)$ and optimism $(\Delta \alpha=0.05)$ subscales. This finding aligns with the observations of Görgens-Ekermans and Herbert (2013), who also reported lower reliabilities of the respective scales in the South African context. These findings indicate that items 13 and 20 can be regarded as problematic items when being used with South African participants.

It was hypothesised that POS would be positively linked to well-being. Support creates a feeling of security and meets the employee's socio-emotional needs (Caesens et al., 2016). Referring to the JD-R theory (Bakker \& Demerouti, 2014), it was argued that job resources, such as POS, would buffer the negative impact of job demands, and that job resources would facilitate motivational processes such as one's desire for growth, which is regarded to be part of psychological well-being. Previous research has already shown that POS is positively linked to well-being (Caesens et al., 2016). The present study supports the research finding by Caesens et al. (2016), showing that POS was positively correlated to wellbeing. Furthermore, POS served as a significant predictor of well-being. It was also suggested that POS would be positively related to PsyCap, arguing that job resources would work in favour of personal resources (Xanthopoulou et al., 2007). Organisational support was previously shown to be linked to PsyCap (Azim \& Dora, 2016; Sihag \& Sarikwal, 2015). This positive link was also found in the present study. POS and PsyCap were positively correlated with each other and POS significantly predicted PsyCap in a regression analysis. The present study hypothesised that PsyCap would be related to well-being because of PsyCap's positive cognitive and behavioural processes, which was also previously shown in research (Avey et al., 2010). This relationship was confirmed in the present study, concurring with Avey et al.'s (2010) findings, revealing a strong positive correlation between PsyCap and well-being, with PsyCap serving as a predictor of well-being. Based on the previously outlined relationship between POS, PsyCap and well-being, it was assumed that PsyCap would mediate the relationship between POS and well-being. Hierarchical regression confirmed that PsyCap fully mediates the relationship between POS and well-being. Mediation analysis using hierarchical regression showed that POS was a significant predictor of PsyCap. Moreover, POS and PsyCap significantly predicted well-being. Interestingly, POS was no longer of predictive value when PsyCap was added as an additional predictor of well-being. This finding shows that PsyCap is 
a full mediator in the relationship between POS and wellbeing. This result supports the assumption that job resources might help personal resources to develop (Xanthopoulou et al., 2007), and that the personal resource of PsyCap contributes to employee well-being (Avey et al., 2010).

Beyond finding support for previous research outcomes regarding the relationships of POS, PsyCap and well-being, the main contribution of this study is that PsyCap mediates the relationship between POS and well-being. Other scholars have already found that PsyCap plays a mediating role in the relationship between instructor support and well-being (Nielsen et al., 2017), as well as in the relationship between social support and well-being (Li et al., 2014). Furthermore, it was found that PsyCap mediates the relationship between POS and depressive symptoms (Liu et al., 2013). These studies indicated that PsyCap plays an important role between support and mental health. The present study is the first study that provides evidence for PsyCap also being a mediator between POS and positive well-being.

Positivity and PsyCap in particular, in combination with a supportive organisational environment, seem to play an important role in terms of employee well-being. The findings from the present study imply that the main contributor towards employee well-being is the development of a positive state of mind, characterised by self-efficacy, hope, optimism and resilience. The present study, therefore, offers valuable insight to organisations that aim to contribute to the wellbeing of their employees. Employees who perceive their organisation to be supportive are more likely to have higher levels of PsyCap, which in turn positively affect their wellbeing. An employee's PsyCap may, therefore, be a valuable resource to deal with the challenges in today's workplace. PsyCap may help employees maintain a healthy level of positive affect and positive psychological functioning. This finding highlights the power of the human psyche and aligns well with the notions of positive psychology. As a consequence, organisations should be interested in facilitating the PsyCap of their employees. Considering the importance of PsyCap as a predictor of well-being, organisations should also acknowledge the important role of a positive and supportive organisational environment. A supportive organisation creates an environment that allows PsyCap to operate on a high level and, therefore, assists employees in maintaining higher levels of well-being. High levels of wellbeing indicate that individuals experience optimal levels of positive affect and positive psychological functioning, which may provide a competitive advantage. The findings from the present study imply that it is not sufficient to provide support; it is also important to specifically target the personal resources of employees, referring to their PsyCap in particular. PsyCap is a construct that is open to development and can be targeted through specific interventions (Luthans et al., 2008, 2010). Implementing PsyCap training in organisations might, therefore, be a valuable addition to already existing human resource development programmes.
The outlined implications may help organisations leverage the well-being of their employees. Nevertheless, the limitations of the present study should be acknowledged.

Firstly, a convenience and snowball sample is not representative of the South African population. It is possible that snowball sampling resulted in a homogenous sample because people within one network are often similar to one another, sharing certain characteristics. The findings can, therefore, not be generalised to the South African population. Secondly, the results are correlational and not causal in nature. It is also possible that employees who express high levels of well-being simply have a more favourable perception of their personal and organisational resources. High levels of positive affect and psychological functioning might be related to better perceptions of one's PsyCap and of organisational support that is available. Causality can, therefore, only be implied by longitudinal or experimental studies. Thirdly, cross-sectional and self-reported data is not always an accurate source of information. Although bias because of CMV is not regarded as an issue, it cannot be guaranteed that participants gave honest and accurate answers.

Future research should further investigate which factors and processes enhance employee well-being and how organisations can create a resourceful environment that will assist their employees in dealing with challenging demands and stress. It is recommended to recruit a larger and more diverse sample that reflects the demographic characteristics of the South African population in a more accurate way in order to be able to generalise the findings. To be able to interpret findings in a causal manner, longitudinal or experimental studies are needed. For instance, the present study could be replicated with multiple assessments a few months apart. Moreover, it is suggested to use other or additional measures to assess the respective constructs in order to reduce bias because of self-reported data. One possible option would be to assess PsyCap using the Implicit Psychological Capital Questionnaire (Luthans et al., 2015).

\section{Conclusion}

This study revealed that PsyCap fully mediates the relationship between POS and well-being, which is a valuable contribution to the existing body of knowledge. This research offered an insight into the underlying mechanism of why organisational support is related to employee well-being. Employees who perceive their organisation to be supportive are more likely to also have the personal resources that help to deal with challenges in the workplace and are, therefore, more likely to experience higher levels of well-being. An employee's PsyCap seems to be an important personal resource that contributes to positive affect and positive psychological functioning. This finding is valuable for organisations because it highlights the importance of a resourceful organisational environment that facilitates the PsyCap of employees and their well-being. 


\section{Acknowledgements Competing interests}

The authors declare that no personal or financial interests were involved that influenced them in writing this article.

\section{Authors' contributions}

This article is the research project of A.R. (Nelson Mandela University) in fulfilment of the requirements for her MA degree and C.H. (Nelson Mandela University) is the project supervisor. A.R. was responsible for writing the literature review, setting up the research design, the process of data collection, data analysis and the write-up. C.H. guided the research process, edited and co-authored this article.

\section{References}

Achor, S. (2011). The happiness advantage: The seven principles that fuel success and performance at work. New York: Random House.

Alarcon, G. M., Bowling, N. A., \& Khazon, S. (2013). Great expectations: A metaanalytic examination of optimism and hope. Personality and Individual Differences, 54(7), 821-827. https://doi.org/10.1016/j.paid.2012.12.004

Aselage, J., \& Eisenberger, R. (2003). Perceived organizational support and psychological contracts: A theortical integration. Journal of Organizational Behavior, 24(5), 491-509. https://doi.org/10.1002/job.211

Avey, J. B., Luthans, F., Smith, R. M., \& Palmer, N. F. (2010). Impact of positive psychological capital on employee well-being over time. Journal of Occupational Health Psychology, 15(1), 17-28. https://doi.org/10.1037/a0016998

Azim, A. M. M., \& Dora, M. T. (2016). Perceived organizational support and organizational citizenship behavior: The mediating role of psychological capital. Journal of Human Capital Development, 9(2), 99-118.

Bakker, A. B., \& Demerouti, E. (2014). Job demands-resources theory. In C. Cooper \& P. Chen (Eds.), Wellbeing: A complete reference guide (pp. 37-64). Chichester: Wiley-Blackwell.

Bandura, A. (1982). Self-efficacy mechanism in human agency. American Psychologist, 37(2), 122-147. https://doi.org/10.1037/0003-066X.37.2.122

Baron, R. M., \& Kenny, D. a. (1986). The moderator-mediator variable distinction in social psychological research: Conceptual, strategic, and statistical considerations. Journal of Personality and Social Psychology, 51(6), 1173-1182. https://doi. org/10.1037/0022-3514.51.6.1173

Boateng, F. D. (2014). Perceived organizational support and police officer effectiveness. International Criminal Justice Review, 24(2), 134-150. https://doi.org/10.1177/ 1057567714536907

Britt, T. W., Shen, W., Sinclair, R. R., Grossman, M. R., \& Klieger, D. M. (2016). How much do we really know about employee resilience? Industrial and Organizational Psychology, 9(2), 378-404. https://doi.org/10.1017/iop.2015.107

Brown, S. P., Jones, E., \& Leigh, T. W. (2005). The attenuating effect of role overload on relationships linking self-efficacy and goal level to work performance. The Journa of Applied Psychology, 90(5), 972-979. https://doi.org/10.1037/0021-9010. of Applied

Caesens, G., Stinglhamber, F., \& Ohana, M. (2016). Perceived organizational support and well-being: A weekly study. Journal of Managerial Psychology, 31(7), 1214-1230. https://doi.org/10.1108/JMP-01-2016-0002

Carver, C. S., Scheier, M. F., \& Segerstrom, S. C. (2010). Optimism. Clinical Psychology Review, 30, 879-889. https://doi.org/10.1016/j.cpr.2010.01.006

Caza, B. B., \& Milton, L. P. (2012). Resilience at work. In K. S. Cameron \& G. M. Spreitzer (Eds.), Oxford handbook of positive organizational scholarship (pp. 895-908) New York, NY: Oxford University Press.

Chen, S., Westman, M., \& Hobfoll, S. E. (2015). The commerce and crossover of resources: Resource conservation in the service of resilience. Stress and Health resources: Resource conservation in the service of
31(2), 95-105. https://doi.org/10.1002/smi.2574

Cohen-Charash, Y., \& Mueller, J. S. (2007). Does perceived unfairness exacerbate or mitigate interpersonal counterproductive work behaviors related to envy? The Journal of Applied Psychology, 92(3), 666-680. https://doi.org/10.1037/00219010.92.3.666

Desrumaux, P., Lapointe, D., Ntsame Sima, M., Boudrias, J. S., Savoie, A., \& Brunet, L. (2015). The impact of job demands, climate, and optimism on well-being and distress at work: What are the mediating effects of basic psychological need satisfaction? Revue Européene de Psychologie Appliquée, 65(4), 179-188. https:// doi.org/10.1016/j.erap.2015.06.003

Dewa, C. S., Loong, D., Bonato, S., Thanh, N., \& Jacobs, P. (2014). How does burnout affect physician productivity? A systematic literature review. BMC Health Services Research, 14(1), 325. https://doi.org/10.1186/1472-6963-14-325

Disabato, D. J., Goodman, F. R., Kashdan, T. B., Short, J. L., \& Jarden, A. (2016). Different types of well-being? A cross-cultural examination of hedonic and eudaimonic well-being. Psychological Assessment, 28(5), 471-482. https://doi.org/10.1037/ pas0000209
Eisenberger, R., Huntington, R., Hutchison, S., \& Sowa, D. (1986). Perceived organizational support. Journal of Applied Psychology, 71(3), 500-507. https:// organizational support. Journal of Apph
doi.org/10.1037/0021-9010.71.3.500

Fida, R., Paciello, M., Tramontano, C., Barbaranelli, C., \& Farnese, M. L. (2015). 'Yes, I can': The protective role of personal self-efficacy in hindering counterproductive work behavior under stressful conditions. Anxiety, Stress, \& Coping, 28(5), 479-499. https://doi.org/10.1080/10615806.2014.969718

Görgens-Ekermans, G., \& Herbert, M. (2013). Psychological capital: Internal and external validity of the psychological capital questionnaire (PCQ-24) on a South African sample. SA Journal of Industrial Psychology, 39(2), 1-13. https://doi. org/10.4102/sajip.v39i2.1131

Hobfoll, S. E. (1989). Conservation of resources. A new attempt at conceptualizing stress. The American Psychologist, 44(3), 513-524. https://doi.org/10.1037/0003066X.44.3.513

Inzlicht, M., Schmeichel, B. J., \& Macrae, C. N. (2014). Why self-control seems (but may not be) limited. Trends in Cognitive Sciences, 18(3), 127-133. https://doi. org/10.1016/j.tics.2013.12.009

Kurtessis, J. N., Eisenberger, R., Ford, M. T., Buffardi, L. C., Stewart, K. A., \& Adis, C. S. (2017). Perceived organizational support: A meta-analytic evaluation of organizational support theory. Journal of Management, 43(6), 1854-1884 https://doi.org/10.1177/0149206315575554

Li, B., Ma, H., Guo, Y., Xu, F., Yu, F., \& Zhou, Z. (2014). Positive psychological capital: A new approach to social support and subjective well-being. Social Behavior and Personality, 42(1), 135-144. https://doi.org/10.2224/sbp.2014.42.1.135

Lindell, M. K., \& Whitney, D. J. (2001). Accounting for common method variance in cross-sectional research designs. Journal of Applied Psychology, 86(1), 114-121. https://doi.org/10.1037/0021-9010.86.1.114

Liu, L., Hu, S., Wang, L., Sui, G., \& Ma, L. (2013). Positive resources for combating depressive symptoms among Chinese male correctional officers: Perceived organizational support and psychological capital. BMC Psychiatry, 13, 89. https:// organizational support and psycholog

Longo, Y., Coyne, I., Joseph, S., \& Gustavsson, P. (2016). Support for a general factor of well-being. Personality and Individual Differences, 100, 68-72. https://doi.org/ 10.1016/j.paid.2016.03.082

Luthans, F., Avey, J. B., Avolio, B. J., \& Peterson, S. J. (2010). The development and resulting performance impact of positive psychological capital. Human Resource Development Quarterly, 21(1), 41-67. https://doi.org/10.1002/hrdq

Luthans, F., Avey, J. B., \& Patera, J. L. (2008). Experimental analysis of a web-based training intervention to develop positive. Academy of Management Learning \& Education, 7(2), 209-221. https://doi.org/10.5465/AMLE.2008.32712618

Luthans, F., Avolio, B. J., Avey, J. B., \& Norman, S. M. (2007). Positive psychological capital: Measurement and relationship with performance and satisfaction Personnel Psychology, 60(3), 541-572. https://doi.org/10.1111/j.1744-6570. 2007.00083

Luthans, F., Youssef-Morgan, C. M., \& Avolio, B. J. (2015). Psychological capital and beyond. New York: Oxford University Press.

Malinowski, P., \& Lim, H. J. (2015). Mindfulness at work: Positive affect, hope, and optimism mediate the relationship between dispositional mindfulness, work
engagement, and well-being. Mindfulness, $6,1250-1262$. https://doi.org/10.1007/ engagement, and well-b

Matin, H. Z., Kalali, N. S., \& Anvari, M. R. A. (2012). Do demographic variables moderate the relationship between job burnout and its consequences? Iranian moderate the relationship between job burn
Journal of Management Studies, 5(1), 47-62.

Nielsen, I., Newman, A., Smyth, R., Hirst, G., \& Heilemann, B. (2017). The influence of instructor support, family support and psychological capital on the well-being of postgraduate students: A moderated mediation model. Studies in Higher Education, 42(11), 2099-2115. https://doi.org/10.1080/03075079.2015.1135116

Olivares-Faúndez, V. E., Gil-Monte, P. R., Mena, L., Jélvez-Wilke, C., \& FigueiredoFerraz, H. (2014). Relationships between burnout and role ambiguity, role conflict and employee absenteeism among health workers. Terapia Psicológica, 32(2), 111-120. https://doi.org/10.4067/S0718-48082014000200004

Oswald, A. J., Proto, E., \& Sgroi, D. (2015). Happiness and productivity. Journal of Labor Economics, 33(4), 789-822. https://doi.org/10.1086/681096

Podsakoff, P. M., \& Organ, D. W. (1986). Self-reports in organizational research: Problems and prospects. Journal of Management, 12(4), 531-544. https://doi. org/10.1177/014920638601200408

Robinson, S. L. (1996). Trust and breach of the psychological contract. Administrative Science Quarterly, 41(4), 574-599. https://doi.org/10.2307/2393868

Ryan, R. M., \& Deci, E. L. (2001). On happiness and human potentials: A review of research on hedonic and eudaimonic well-being. Annual Review of Psychology, 52(1), 141-166. https://doi.org/10.1146/annurev.psych.52.1.141

Ryff, C. D., \& Singer, B. H. (2008). Know thyself and become what you are: A eudaimonic approach to psychological well-being. Journal of Happiness Studies, 9(1), 13-39. approach to psychological well-being. Journal
$\mathrm{https} / / /$ doi.org/10.1007/s10902-006-9019-0

Schneider, S. L. (2001). In search of realistic optimism. American Psychologist, 56(3), 250-263. https://doi.org/10.1037//0003-066X.56.3.250

Seligman, M. E. P. (2002). Authentic happiness: Using the new positive psychology to realize your potential for lasting fulfillment. New York: Simon and Schuster.

Seligman, M. E. P., \& Csikszentmihalyi, M. (2000). Positive psychology: An introduction. American Psychologist, 55(1), 5-14. https://doi.org/10.1037//0003-066X.55.1.5

Shen, Y., Jackson, T., Ding, C., Yuan, D., Zhao, L., Dou, Y., \& Zhang, Q. (2014). Linking perceived organizational support with employee work outcomes in a Chinese context: Organizational identification as a mediator. European Management Journal, 32(3), 406-412. https://doi.org/10.1016/j.emj.2013.08.004 
Sihag, P., \& Sarikwal, L. (2015). Effect of perceived organizational support on psychological capital - A study of IT industries in Indian framework. EJBO-Electronic psychological capital -A study of IT industries in Indian framework.
Journal of Business Ethics and Organization Studies, 20(2), 19-26.

Smoktunowicz, E., Baka, L., Cieslak, R., Nichols, C. F., Benight, C. C., \& Luszczynska, A. (2015). Explaining counterproductive work behaviors among police officers: The indirect effects of job demands are mediated by job burnout and moderated by job control and social support. Human Performance, 28(4), 332-350. https://doi. org/10.1080/08959285.2015.1021045

Snyder, C. R. (2002). Hope theory: Rainbows in the mind. Psychological Inquiry, 13(4) 249-275. https://doi.org/10.1207/S15327965PLI1304_01

Souri, H., \& Hasanirad, T. (2011). Relationship between resilience, optimism and psychological well-being in students of medicine. Procedia - Social and Behavioral Sciences, 30, 1541-1544. https://doi.org/10.1016/j.sbspro.2011. 10.299

Stajkovic, A. D., \& Luthans, F. (1998). Social cognitive theory and self-efficacy: Going beyond traditional motivational and behavioral approaches. Organizational Dynamics, 26(4), 62-74. https://doi.org/10.1016/S0090-2616(98)90006-7

Straume, L. V., \& Vitters $\emptyset$, J. (2015). Well-being at work: Some differences between life satisfaction and personal growth as predictors of subjective health and sick-leave. Journal of Happiness Studies, 16(1), 149-168. https://doi.org/10.1007/s10902014- 9502-y

Taber, K. S. (2017). The use of Cronbach's alpha when developing and reporting research instruments in science education. Research in Science Education. Advance online publication. https://doi.org/10.1007/s11165-016-9602-2
Tennant, R., Hiller, L., Fishwick, R., Platt, S., Joseph, S., Weich, S., ... Stewart-Brown, S. (2007). The Warwick-Edinburgh Mental Well-Being Scale (WEMWBS): Development
and UK validation. Health and Quality of Life Outcomes, 5(63), 1-13. https://doi. and UK validation. Health and

Vohs, K. D., \& Schmeichel, B. J. (2002). What makes hope hopeful? The relationship between hope and self-regulation. Psychological Inquiry, 13(4), 318-321.

Walters, G., \& Raybould, M. (2007). Burnout and perceived organisational support among front-line hospitality employees. Journal of Hospitality and Tourism Management, 14(2), 144-156. https://doi.org/10.1375/jhtm.14.2.144

Waterman, A. S., Schwartz, S. J., \& Conti, R. (2008). The implications of two conceptions of happiness (hedonic enjoyment and eudaimonia) for the understanding of intrinsic motivation. Journal of Happiness Studies, 9(1), 41-79. https://doi. org/10.1007/s10902-006-9020-7

Worley, J. A., Fuqua, D. R., \& Hellman, C. M. (2009). The survey of perceived organizational support: Which measure should we use? SA Journal of Industria Psychology, 35(1), 112-116. https://doi.org/10.4102/sajip.v35i1.754

Xanthopoulou, D., Bakker, A. B., Demerouti, E., \& Schaufeli, W. B. (2007). The role of personal resources in the job demands-resources model. International Journal of Stress Management, 14(2), 121-141. https://doi.org/10.1037/1072-5245.14.2.121

Youssef-Morgan, C. M., \& Luthans, F. (2015). Psychological capital and well-being. Stress and Health, 31, 180-188. https://doi.org/10.1002/smi.2623

Zoellner, T., \& Maercker, A. (2006). Posttraumatic growth in clinical psychology - A critical review and introduction of a two component model. Clinical Psychology Review, 26(5), 626-653. https://doi.org/10.1016/j.cpr.2006.01.008 